\title{
An evolving role for endobronchial ultrasonography in the intensive care unit
}

\author{
Or Kalchiem-Dekel $^{1 \#}$, Saamia Hossain ${ }^{1 *}$, Cosmin Gauran ${ }^{2}$, Jason A. Beattie ${ }^{1}$, Bryan C. Husta ${ }^{1}$, \\ Robert P. Lee ${ }^{1}$, Mohit Chawla ${ }^{1}$
}

${ }^{1}$ Section of Interventional Pulmonology, Pulmonary Service, Department of Medicine, Memorial Sloan Kettering Cancer Center, New York, NY, USA; ${ }^{2}$ Department of Anesthesia and Critical Care Medicine, Memorial Sloan Kettering Cancer Center, New York, NY, USA

Contributions: (I) Conception and design: O Kalchiem-Dekel, S Hossain, M Chawla; (II) Administrative support: None; (III) Provision of study materials or patients: None; (IV) Collection and assembly of data: O Kalchiem-Dekel, S Hossain, M Chawla; (V) Data analysis and interpretation: None; (VI) Manuscript writing: All authors; (VII) Final approval of manuscript: All authors.

\#These authors contributed equally to this work.

Correspondence to: Mohit Chawla, MD, FCCP. Section of Interventional Pulmonology, Pulmonary Service, Department of Medicine, Memorial Sloan Kettering Cancer Center, New York, NY 10065, USA. Email: chawlam1@mskcc.org.

\begin{abstract}
Endobronchial ultrasound (EBUS) bronchoscopy is an established minimally-invasive modality for visualization, characterization, and guidance of sampling of paratracheal and parabronchial structures and tissues. In the intensive care unit (ICU), rapidly obtaining an accurate diagnosis is paramount to the management of critically ill patients. In some instances, diagnosing and confirming terminal illness in a critically ill patient provides needed closure for patients and their loved ones. Currently available data on feasibility, safety, and yield of EBUS bronchoscopy in critically ill patients is based on single center experiences. These data suggest that in select ICU patients convex and radial probe-EBUS bronchoscopy can serve as useful tools in the evaluation of mediastinal lymphadenopathy, central airway obstruction, pulmonary embolism, and peripheral lung lesions. Barriers to the use of EBUS bronchoscopy in the ICU include: (I) requirement for dedicated equipment, prolonged procedure time, and bronchoscopy team expertise that may not be available; (II) applicability to a limited number of patients and conditions in the ICU; and (III) technical difficulty related to the relatively large outer diameter of the convex probe-EBUS bronchoscope and an increased risk for adverse cardiopulmonary consequences due to intermittent obstruction of the artificial airway. While the prospects for EBUS bronchoscopy in critically ill patients appear promising, judicious patient selection in combination with bronchoscopy team expertise are of utmost importance when considering performance of EBUS bronchoscopy in the ICU setting.
\end{abstract}

Keywords: Endobronchial ultrasonography; bronchoscopy; intensive care unit

Submitted Feb 12, 2020. Accepted for publication Apr 21, 2020.

doi: 10.21037/jtd-2019-ipicu-09

View this article at: http://dx.doi.org/10.21037/jtd-2019-ipicu-09

\section{Introduction}

The introduction of endobronchial ultrasound (EBUS) into the armamentarium of diagnostic bronchoscopy tools has greatly improved our ability to visualize, characterize, and adequately sample paratracheal and parabronchial structures in addition to airway mucosal, submucosal, and endobronchial tissues. Radial-probe (rp) EBUS was introduced in the early 1990s (1) and was initially designed for visualization of central airway wall abnormalities and guidance of conventional transbronchial needle aspiration (TBNA). With the advent of convex-probe (cp) EBUS, this use has been largely abandoned. Currently, rpEBUS is mostly used for localizing and characterizing peripheral lung lesions to safely and reliably guide sampling $(2,3)$. Introduced one decade following rpEBUS, cpEBUS 
has revolutionized sampling of mediastinal and hilar paratracheal and parabronchial tissues, specifically lymph nodes and masses (4). cpEBUS replaced mediastinoscopy as the gold standard for evaluating lymph node involvement in lung cancer staging (5). It is also considered a first-line modality for mediastinal tissue sampling for a variety of other benign and malignant conditions (5).

Advances in therapy for solid organ neoplasms, in particular lung cancer, have led to prolonged patient survival. Recent data indicates improved ICU outcomes in this patient population (6). Hence, patients with suspected or established thoracic malignancies are more commonly requiring intensive care unit (ICU) care at a variety of junctures in their disease course (7). EBUS may have utility in the evaluation of critically ill patients with a variety of central airway, mediastinal, and peripheral lung conditions, whether, inflammatory, infectious, or neoplastic in nature (8), as well as in some thoracic vascular abnormalities (9). Intensivists may therefore increasingly encounter situations where EBUS-guided tissue acquisition is useful to establish crucial diagnoses and, at times, confirm terminal illness to provide needed closure for patients as well as their loved ones. Nevertheless, thus far the use of different EBUS modalities in critically ill patients has not evolved beyond single center experiences in the literature. This is likely a result of several factors: (I) EBUS is considered an advanced bronchoscopic modality, which may not be available for intensivists due to lack of access to necessary equipment or lack of expertise in procedure performance (5); (II) EBUS bronchoscopy is applicable to a limited number of patients and conditions in the ICU; (III) the cpEBUS bronchoscope is relatively bulky compared with conventional diagnostic or therapeutic bronchoscopes and thus occupies more of the artificial airway cross-sectional area, requiring a larger size artificial airway, imposing potential difficulty in gas exchange, and raising concern over deleterious hemodynamic and respiratory consequences $(10,11)$; and (IV) EBUS-guided procedures require a systematic approach and are therefore more time-prolonged compared with bronchoscopy for other indications, which may impose further risk for adverse procedure-related adverse effects in a critically ill patient.

In this review, we describe technical aspects of performing EBUS bronchoscopy and TBNA in critically-ill patients, present current literature pertaining to potential indications for EBUSguided procedures in the ICU and delineate complimentary modalities. Although our primary focus is on cpEBUS, the utility of rpEBUS in critically ill patients is also discussed.

\section{Bronchoscopy and EBUS during positive- pressure mechanical ventilation}

Over the past four decades, flexible bronchoscopy has been increasingly used by intensivists in the ICU for diagnostic as well as therapeutic purposes. Common indications for diagnostic bronchoscopy in critically ill patients include evaluation for airway and lung infection, localization of airway bleeding, and assessment of airway injury or compromise. Therapeutic bronchoscopy may be indicated for aspiration of the tracheobronchial tree, removal of foreign bodies, and guiding percutaneous tracheostomy tube, endobronchial blocker, or double-lumen endotracheal tube (ETT) placement $(12,13)$. Although bronchoscopy may be feasible and beneficial in the most critically ill of patients (14), the bronchoscopist must be aware of and be prepared for several pathophysiological consequences that bronchoscopy may impose on patients receiving positive pressure ventilation.

Partial obstruction of the artificial airway by the insertion tube of the bronchoscope results in significant reduction in the cross-sectional area of the artificial airway (Figure 1). To illustrate, a typical therapeutic bronchoscope with an outer diameter of $6.0 \mathrm{~mm}$ reduces the cross-sectional area of an $8.5-\mathrm{mm}$ ETT to that of a $5.0-\mathrm{mm}$ ETT (10). As a consequence, bronchoscopy may result in reduction in tidal volume, alveolar de-recruitment, increase in airway resistance, impairment of gas exchange, and increase in intrinsic positive end-expiratory pressure (PEEP), all leading to compromised respiratory $(10,15-19)$ and cardiovascular $(10,11,20)$ dynamics. Increase in intracranial pressure has also been described; the degree and the clinical significance of which may vary among different patient populations (21-23). Furthermore, tidal volume and alveolar recruitment can be further compromised by suctioning maneuvers (24-26), while respiratory system compliance, airway resistance, and oxygenation can be adversely affected by performance of bronchoalveolar lavage $(27,28)$. Some of these potential adverse effects can be attenuated by increasing the fraction of inspired oxygen $\left(\mathrm{FiO}_{2}\right)$ to 1.0 $(13,15)$, using the smallest diameter bronchoscope that will allow achievement procedure goals $(11,19)$, having an artificial airway that is at least $2 \mathrm{~mm}$ wider than the outer diameter of the bronchoscope $(17,29)$, minimizing suction $(24,26)$ and shortening overall procedure time. In addition, it has been shown that pressure-controlled 


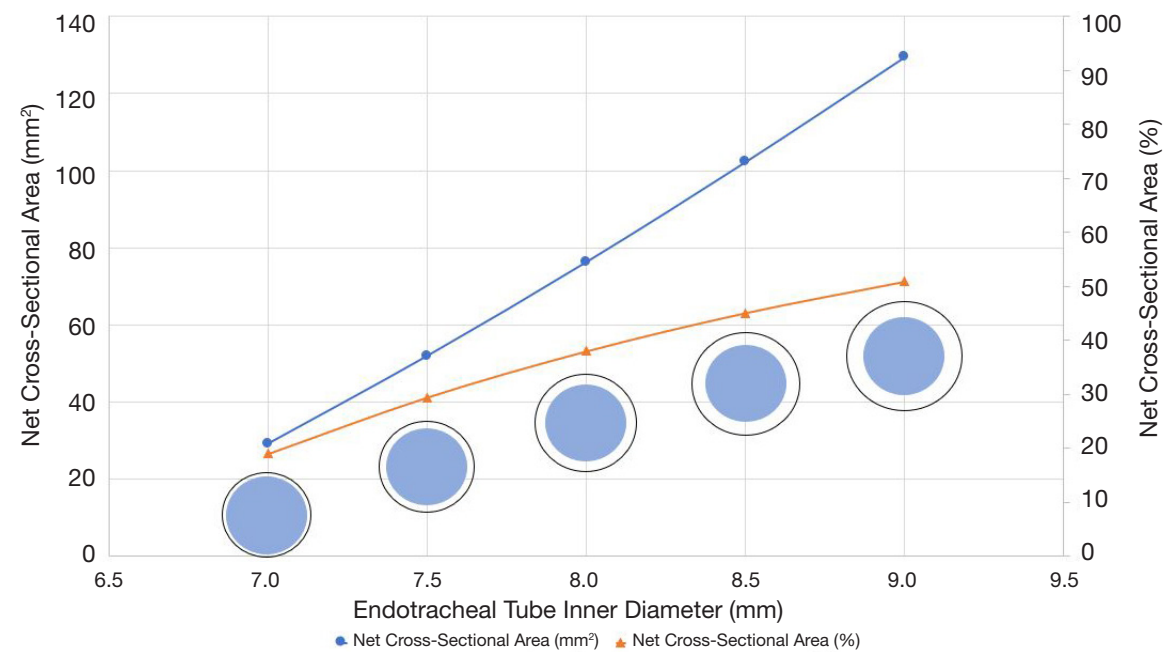

Figure 1 Effective reduction in the cross-sectional area of the endotracheal tube during bronchoscopy with a 6.3-mm insertion tubediameter convex probe-EBUS bronchoscope (diagrams drawn at scale). EBUS, endobronchial ultrasound.

Table 1 Dimensions and technical specifications of commercial convex-probe EBUS endoscopes

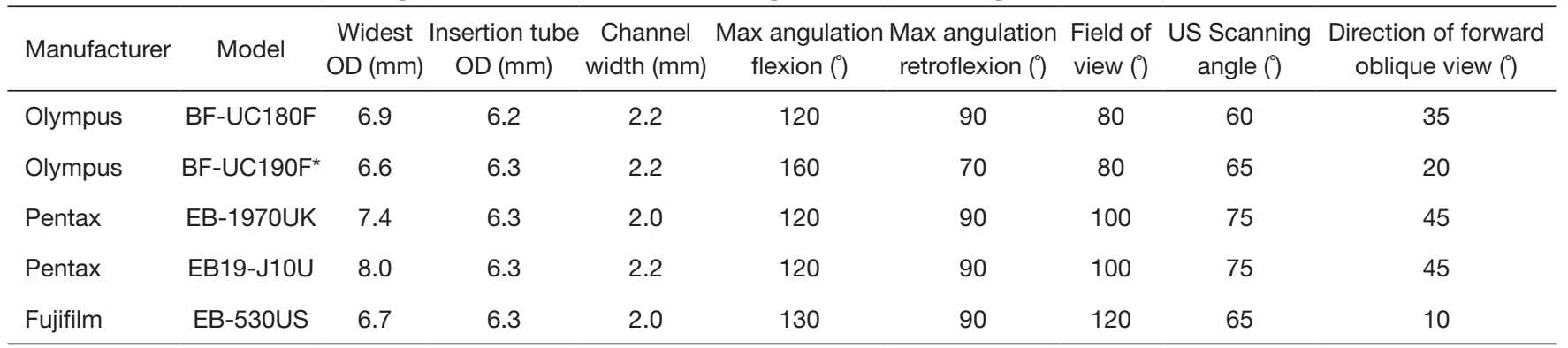

*, not commercially available as of the time of publication. EBUS, endobronchial ultrasound; OD, outer diameter; US, ultrasound.

ventilation mode may be preferable to volume-controlled mode by attenuating the decrease in tidal volume (17) and the increase in intrinsic PEEP (18). Nevertheless, pressurecontrolled ventilation will likely require an increase in the inspiratory pressure in order to deliver the necessary tidal volume during bronchoscopy. It is therefore crucial to decrease the inspiratory pressure to pre-procedure levels before removal of the bronchoscope to avoid excessive pressure transmission to the alveoli and potential barotrauma following bronchoscope withdrawal (17). This can potentially be avoided with volume-targeted, pressurelimited hybrid ventilation modes; however, no data is currently available to support this hypothesis. Additionally, neuromuscular blockade during the procedure may attenuate some of the aforementioned effects by improving patient-ventilator synchrony. There is no available data to support this hypothesis as well.

All the aforementioned adverse cardiorespiratory effects of bronchoscopy in mechanically ventilated patients may potentially be further amplified by cpEBUS bronchoscopy, which utilizes a 6.7 to $8.0 \mathrm{~mm}$ distal end outer diameter integrated ultrasonic bronchoscope (Table 1), thus occupying a relatively larger cross-sectional area of the artificial airway (Figure 1). In addition, performance of TBNA may require inflation of a latex balloon fitted around the ultrasound probe in order to provide contrast interphase and improve visualization. This balloon can be inflated up to $20 \mathrm{~mm}$ in diameter (Figure 2), which can further compromise gas exchange. Furthermore, a relatively prolonged procedure time needs to be accounted for, when performing cpEBUSguided TBNA, compared with other diagnostic modalities of bronchoscopy such as bronchoalveolar lavage. All 

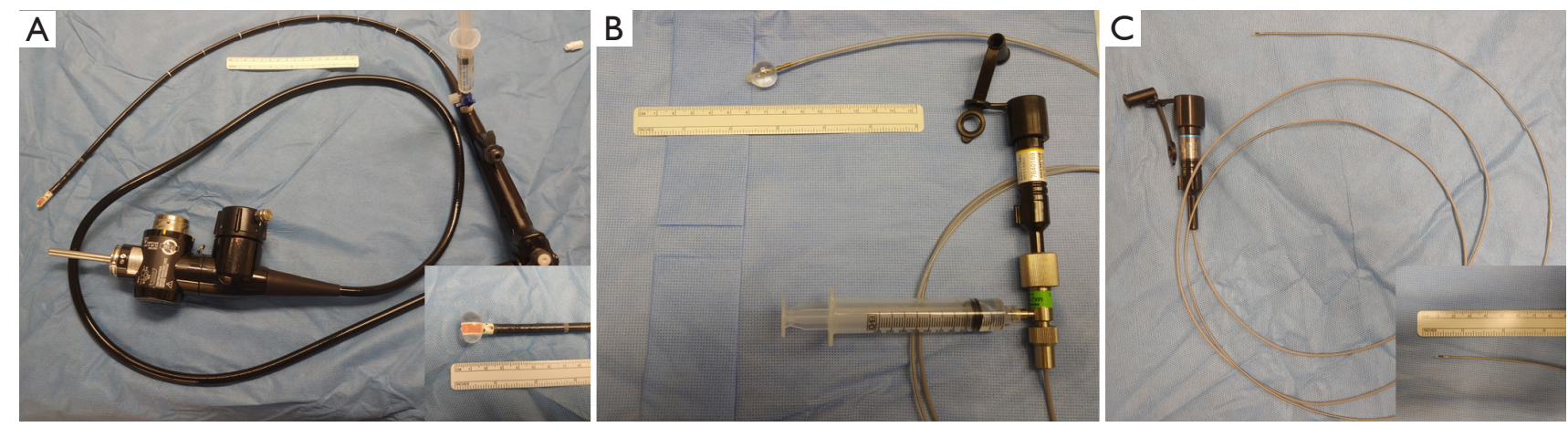

Figure 2 Convex and radial endobronchial ultrasound equipment. (A) Olympus ${ }^{\mathrm{TM}}$ convex probe-EBUS (BF-UC180F) bronchoscope. Inset showing inflated water-filled balloon over the ultrasound probe; (B) Olympus ${ }^{\mathrm{TM}}$ 2.6-mm radial EBUS probe (UM-BS20-26R) fitted with inflatable guide sheath-mounted saline-filled balloon; and (C) Olympus ${ }^{\mathrm{TM}}$ 1.7-mm radial EBUS probe (UM-S20-20R). Inset showing a close-up of the radial ultrasound probe tip.

of these adverse consequences have the potential to be further augmented in critically-ill mechanically ventilated patients, who are likely to harbor compromised respiratory mechanics due to the disease state that has resulted in their respiratory failure.

We provide technical specifications of commercial EBUS bronchoscopes in Table 1. Although the diameter of the ultrasound probe is wider than that of the insertion tube, it is the insertion tube that occupies the artificial airway for a majority of the procedure time. The outer diameter of currently available EBUS bronchoscopes' insertion tube is in the range of 6.2 to $6.3 \mathrm{~mm}$. It is therefore recommended to perform cpEBUS bronchoscopy via an ETT that is at least $8.0 \mathrm{~mm}$ in diameter (Figure 1). For tracheostomized patients, our experience is to cut the inner cannula tube, leaving the ventilator adaptor connected to tracheostomy, thus taking full advantage of the outer cannula lumen size for bronchoscope passage, while allowing ongoing mechanical ventilation.

Performance of EBUS-TBNA is a multidisciplinary team effort. Depending on the healthcare system and setting, the team may include any combination of physicians, advanced practice providers, nurses, respiratory therapists, patient care technicians, surgical technologists, cytotechnologists, and anesthesia providers. Following careful review of available imaging, an experienced bronchoscopist proficient in EBUS and EBUS-TBNA performance is likely to identify target lesions and acquire specimens within a shorter procedure time. Furthermore, an assistant who is experienced in technical handling of the EBUS needle, including preparation and loading of the needle unto the bronchoscope channel as well as processing of the procured specimens, is likely to facilitate performance of the procedure. Rapid on-site evaluation (ROSE) of cytologic material has been shown to be associated with fewer needle passes per lesion and potentially shorter procedure time $(5,30)$. Although requiring further expertise in specimen processing on part of the procedure team, implementing ROSE can potentially further shorten procedure time $(8,31)$. Finally, in some instances, bronchoscopy may necessitate frequent adjustment of the ventilator settings and titration of sedatives and analgesics, and thus a separate provider to monitor vital signs, control ventilator settings, and titrate intravenous medications, can be invaluable for that purpose.

In summary, performance of EBUS-TBNA in criticallyill mechanically ventilated patients requires: (I) judicious patient selection in terms of indications, cardiorespiratory status, and airway access; (II) critical review of available imaging for procedure planning and target site identification; and (III) performance by an experienced multidisciplinary team in attempt to maximize the yield while minimizing procedure time.

\section{Utility of convex-probe EBUS and transbronchial needle aspiration in the ICU}

Convex-probe EBUS allows visualization and guides sampling of mediastinal and hilar structures (4). Lymph node stations accessible via cpEBUS include 2, 3p, 4, 7, 10, 11 , and in some instances 12 (32-34). In addition, cpEBUS has an established role in identifying, characterizing, and sampling mediastinal and lung lesions other than lymph 
Table 2 Major publications describing the performance of convex-probe EBUS-TBNA in critically ill patients

\begin{tabular}{|c|c|c|c|c|c|c|c|c|c|c|c|c|}
\hline Publication & $\mathrm{n}$ & $\begin{array}{l}\text { Median } \\
\text { age } \\
\text { (years) }\end{array}$ & Airway & $\begin{array}{c}\text { Ventilator } \\
\text { mode }\end{array}$ & $\begin{array}{l}\text { Median } \\
\text { PEEP } \\
\left(\mathrm{cmH}_{2} \mathrm{O}\right)\end{array}$ & $\begin{array}{l}\text { Median } \\
\mathrm{FiO}_{2}(\%)\end{array}$ & $\begin{array}{l}\text { Median number } \\
\text { of sampling } \\
\text { sites }\end{array}$ & $\begin{array}{c}\text { Median } \\
\text { number of } \\
\text { needle passes }\end{array}$ & $\begin{array}{c}\text { Procedure } \\
\text { length } \\
\text { (minutes) }\end{array}$ & ROSE & $=\begin{array}{c}\text { Diagnostic } \\
\text { yield }(\%)\end{array}$ & Complications \\
\hline $\begin{array}{l}\text { Chichra } \\
\text { et al., } \\
2015(48)^{*}\end{array}$ & 8 & $\mathrm{~N} / \mathrm{A}$ & N/A & N/A & N/A & 40 & N/A & N/A & $\mathrm{N} / \mathrm{A}$ & N/A & 87 & None \\
\hline $\begin{array}{l}\text { Decavèle } \\
\text { et al., } \\
2016 \text { (8) }\end{array}$ & 4 & 63 & $\begin{array}{c}\text { ETT or } \\
\text { LMA }\end{array}$ & N/A & 5 & 40 & 1 & 4 & N/A & Yes & 75 & None \\
\hline
\end{tabular}

*, published in abstract form only. EBUS, endobronchial ultrasound; ETT, endotracheal tube; $\mathrm{FiO}_{2}$, fraction of inspired oxygen; LMA, laryngeal mask airway; PCV, pressure controlled ventilation; PEEP, positive end-expiratory pressure; ROSE; rapid onsite evaluation; TBNA, transbronchial needle aspiration.

nodes for a variety of benign and malignant conditions (35-37). Other less-established utilities include assessment of mediastinal and hilar vasculature (see below), examination and sampling of the pericardium (38-40), and drainage of loculated pleural effusions (41).

Needle aspiration is performed under direct sonographic vision using a dedicated cpEBUS-TBNA needle. For common indications, commercially available 21 - or 22-gauge $(G)$ needles were shown to be safe and equally effective in providing adequate diagnostic yield (5). More recently, a 19G needle has become commercially available and may provide the advantage of yielding larger cell blocks, possibly allowing to reduce the number of needle passes and overall procedure time, without compromising diagnostic accuracy (42-44). Biopsy specimens can also be obtained by transbronchial forceps introduced into the target lesion via the bronchial wall opening already established by the TBNA needle, thus providing histology-grade specimens and potentially increasing the diagnostic yield in certain benign and malignant conditions $(45,46)$.

In the ambulatory patient population, cpEBUS-TBNA is considered a relatively safe procedure with an overall low complication rate (21); however, one should anticipate a higher risk for serious complications, such as bleeding, infection, or pneumothorax in critically ill patients, by virtue of their critical illness, as these patients are more likely to be coagulopathic, immune compromised, and receive positive pressure ventilation, respectively (47).

We summarize current literature describing performance of cpEBUS-TBNA in critically-ill, mechanically ventilated patients in Table 2. Koh et al. retrospectively described their experience performing cpEBUS-TBNA in 6 mechanically ventilated patients that presented a diagnostic dilemma (31). rpEBUS-guided sampling of lung lesions was additionally performed in 2 of the 6 patients. All procedures were performed with a $22 \mathrm{G}$ cpEBUS needle and with an ETT as an artificial airway while the patients were maintained on pressure-controlled ventilation, $\mathrm{PEEP}$ of $5 \mathrm{cmH}_{2} \mathrm{O}$, and an $\mathrm{FiO}_{2}$ of 1.0. The average procedure time was 52 minutes with a range of 20-110 minutes and no major complications were recorded. A diagnosis was made in $83 \%$ of cases, all of whom had malignant disease, allowing guidance of management and therapy in all diagnosed cases (31).

Decavèle et al. performed cpEBUS-TBNA in 9 criticallyill patients, four of whom were mechanically ventilated (8). Airway access was via ETT for 3 patients and via laryngeal mask airway for the remaining patient. PEEP was in the range of 5 to $7 \mathrm{cmH}_{2} \mathrm{O}$ and the $\mathrm{FiO}_{2}$ was maintained in the range of 0.35 to 0.60 . A diagnosis of malignancy was established in 3 out of 4 patients and lead to change in management in 2 of 3 patients (8).

Published in abstract form only, Chichra et al. reported the diagnostic yield of cpEBUS-TBNA in 8 consecutive medical ICU patients to be $87 \%$, resulting in change in management in $71 \%$ of diagnosed patients. A majority of diagnosed patients (4 out of 7) had malignant disease (48). In a separate case report, Chichra et al. elaborated on a case of cryptococcal right hilar mass diagnosed with EBUSTBNA (49).

In summary, cpEBUS-TBNA can be considered a useful 
tool in establishing the diagnosis of metastatic malignancy in an otherwise undiagnosed ICU patient with mediastinal and hilar lymphadenopathy. This added diagnostic information can markedly enhance clinical care through clarifying appropriate choices towards curative or palliative treatment regimens.

\section{Conventional TBNA in critically ill patients}

Until the introduction of cpEBUS, conventional bronchoscopic TBNA of mediastinal and hilar lesions was performed with guidance based on anatomical landmarks and pre-procedure CT imaging (50). This could be supplemented by inspection with a balloon-tipped rpEBUS probe (Figure 2), that can be introduced via the working channel of a conventional bronchoscope (51). There exists a dearth of literature describing performance of conventional TBNA in critically ill patients and the limited existing data supports the utility of cpEBUS in this setting. Ghamande et al. retrospectively described their experience performing 22 bronchoscopic conventional TBNA procedures for mediastinal and hilar lymph nodes or masses in eight patients receiving mechanical ventilation in the ICU (52). The diagnostic yield was $62.5 \%$ and demonstrated malignant etiology in all positive cases. The authors reported no complications related to the procedure in all cases (52). In North America, the practice of conventional TBNA for mediastinal lymph node sampling has been largely abandoned in favor of cpEBUS-guided TBNA and is generally underutilized, as evidenced by recent training and practice surveys $(53,54)$.

\section{Transesophageal access to mediastinal structures}

Endoscopic ultrasonography (EUS) can be performed via the esophagus and proximal stomach to visualize and guide fine needle aspiration (FNA) sampling of mediastinal lymph node stations 5, 6, 8 and 9, which are not accessible by cpEBUS (55), mediastinal stations $2 \mathrm{~L}, 4 \mathrm{~L}$, and $7(55,56)$, certain lung parenchymal lesions (57), the postero-inferior pericardium (58), and the left adrenal gland (59). This procedure can be performed with a cpEBUS bronchoscope or a dedicated EUS endoscope $(60,61)$. In certain critically ill patients, this approach may be preferable since it does not necessitate obstruction of the artificial airway with the bronchoscope (62); however, similar to endobronchial sonography, the transesophageal approach requires expertise in trans-esophageal endoscopy, sonographic imaging, and FNA sampling of mediastinal structures.

Data regarding the performance of trans-esophageal endoscopy and lymph node sampling in critically ill patients is limited. Berzosa et al. retrospectively described a single center experience in performing 64 EUS procedures on 63 ICU patients, 45 of which were mechanically ventilated. Procedures were performed by trained gastroenterologists using Pentax ${ }^{\mathrm{TM}}$ EG-3630U or FG-36UX endoscopes. The authors reported change in management in $97 \%$ of the cases. They additionally reported a $9 \%$ complication rate. All complications were transient and included transient hypoxia $(n=4)$, nonsustained cardiac arrhythmias $(n=1)$, and transient hypotension $(\mathrm{n}=1)(63)$.

Bhaskar et al. describe four cases of trans-esophageal cpEBUS FNA of mediastinal lymph nodes performed on intubated patients, three of whom were critically ill. Among the critically ill patients, FNA revealed a suppurative infection in two cases and a malignancy in the third. ROSE was available in all cases. All results led to a change in management. No complications were reported in any of the cases (64).

\section{Convex-probe EBUS in the evaluation of mediastinal and hilar vasculature}

The current standard of evaluating abnormalities of the pulmonary circulation includes pulmonary arterial angiography, pulmonary artery-enhanced CT angiography (CTA), and in certain instances lung perfusion scintigraphy. Critically ill patients, however, are at times not suitable candidates for these studies due to clinical instability or contraindication to intravenous iodine-based contrast. The intimate association of the central pulmonary arteries with the trachea and the central airways, without lung tissue in the intermediary, allows them to be visualized with cpEBUS and even accessed via the transbronchial route. This can supplement data provided by more readily-available and less invasive modalities, such as transthoracic echocardiography.

Utilization of cpEBUS in incidental identification or confirmation of pulmonary embolism (PE) was described in several case reports $(65,66)$. In an innovative pilot study, Aumiller et al. aimed to explore the feasibility of confirming a diagnosis of central PE with cpEBUS in 32 non-critically ill patients with central PE, established by CTA (67). Of a total 101 emboli identified on CTA, cpEBUS examination has detected 97 emboli, thus establishing a 96\% detection rate. The authors note that the 4 undetectable emboli 
A
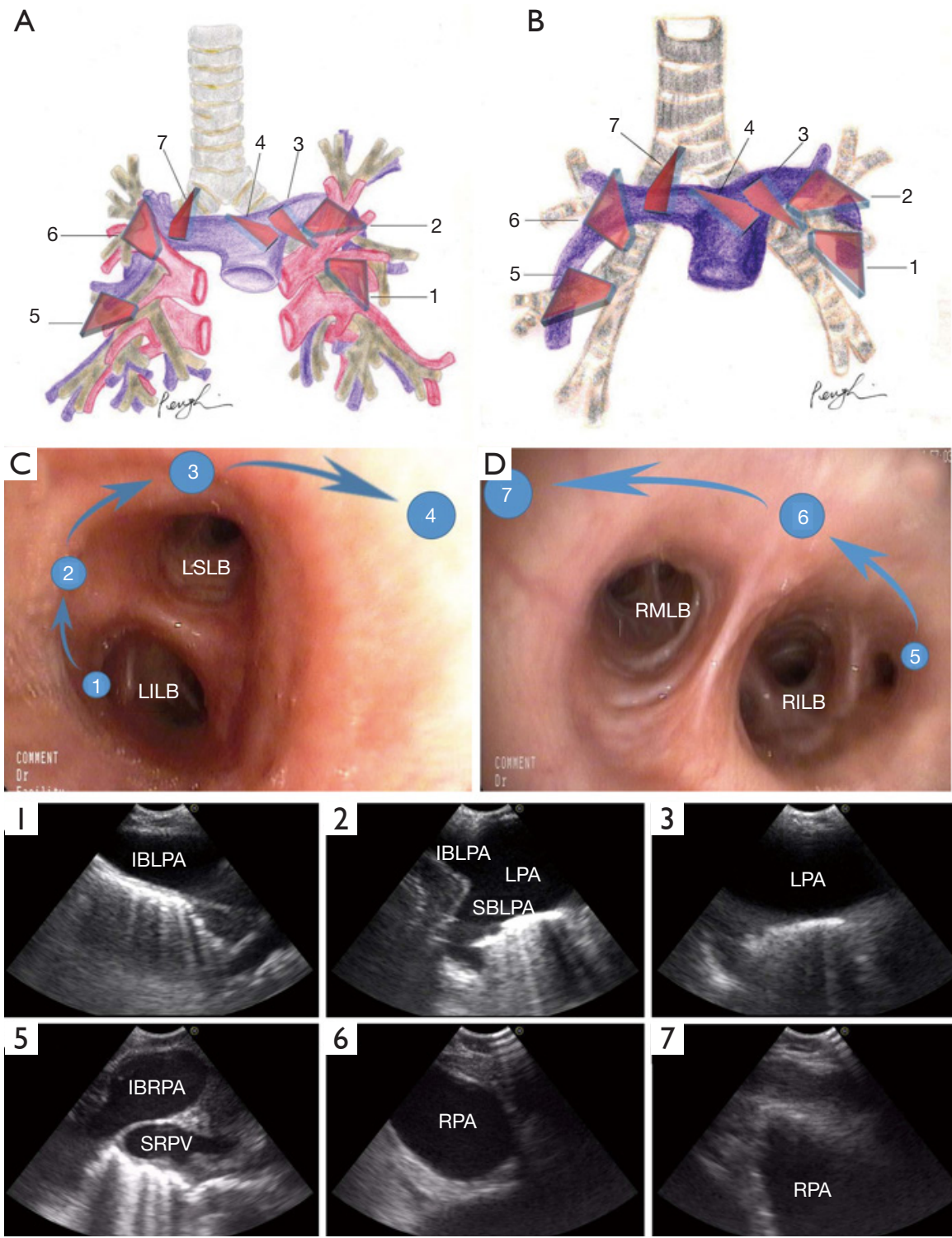

5
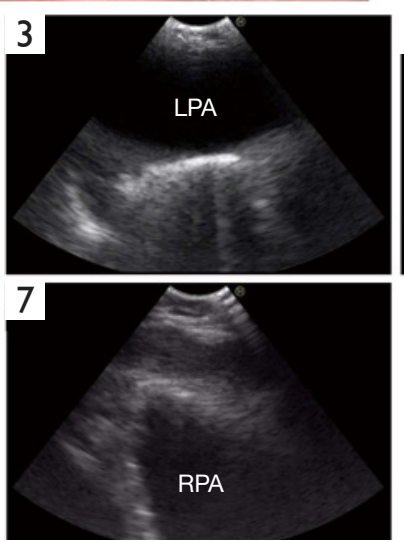

\section{(1)}

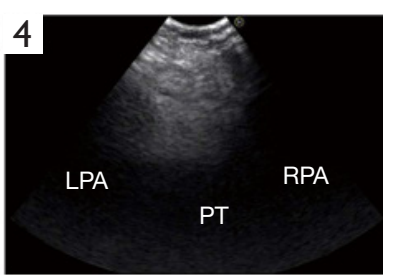

Figure 3 Illustrated, endobronchial, and sonographic maps for EBUS pulmonary artery scanning. Numbers represent the scanning order and corresponding trapezoids show the orientation of the ultrasound probe. (A) Illustrated anatomic view demonstrating an anterior view of the central pulmonary arteries (violet) and veins (red); (B) illustrated anatomic view demonstrating a posterior view of the central pulmonary arteries (violet) without veins; (C) endobronchial roadmap and sonographic appearance of the left pulmonary artery by EBUS; and (D) endobronchial roadmap and sonographic appearance of the right pulmonary artery by EBUS [reproduced from (9) with permission from Fournal of Thoracic Disease Editorial Office]. EBUS, endobronchial ultrasound; IBLPA, inferior branch of left pulmonary artery; LILB, left inferior lobar bronchus; LPA, left pulmonary artery; LSLB, left superior lobar bronchus; RILB, right inferior lobar bronchus; RMLB, right middle lobar bronchus; SBLPA, superior branch of left pulmonary artery; PT, pulmonary trunk; RPA, right pulmonary artery; IBRPA, inferior branch of right pulmonary artery; SRPV, superior right pulmonary vein.

were in peripheral locations that were unlikely to be easily visualized by cpEBUS examination. It should be noted, that bronchoscopists participating in this study were allowed to review the CTA images prior to each procedure. Based on the work published by Aumiller et al., Li et al. established a systematic map of the central pulmonary arteries (Figure 3) by performing cpEBUS bronchoscopy on 14 adults without known pulmonary endarterial disease (9). In both studies, 
cpEBUS was performed by skilled bronchoscopists and on non-critically ill patients. To illustrate, the length of time required to evaluate the central pulmonary arteries by cpEBUS examination ranged between 1 and 5 minutes, across both studies $(9,67)$. Although caution should be exercised when extrapolating these data to the ICU setting, it is reasonable to hypothesize that in carefully selected critically ill patients and at the hands of an experienced cpEBUS bronchoscopist, rapid evaluation of the pulmonary arteries for PE appears feasible.

In addition to visualizing the pulmonary vasculature, several case reports have established utility of diagnostic cpEBUS bronchoscopy in characterizing and sampling malignant pulmonary artery endovascular lesions, such as primary pulmonary artery $(68,69)$ and vein $(70)$ tumors and pulmonary arterial tumor emboli $(71,72)$, as well as pulmonary artery involvement with benign diseases, such as echinococcosis (73).

\section{Radial-probe EBUS}

Radial EBUS miniaturized probes can be used to characterize airway wall anatomy and surrounding structures by providing a 360-degree sonographic image. These probes are advanced via the working channel of the bronchoscope and positioned endobronchially against the target airway wall, thus not necessitating a dedicated bronchoscope; however, they do not allow real-time guidance for sampling of target lesions.

Critical airway stenosis due to extrinsic compression by rapidly-expanding mediastinal mass, endobronchial lesions, or benign stricture is an uncommon, but dreadful situation that may be encountered in the ICU (74). The Olympus ${ }^{\mathrm{TM}}$ $20-\mathrm{MHz}, 2.5-\mathrm{mm}$ diameter probe can be introduced via a 2.8-mm working channel of a bronchoscope and can be fitted with a water-inflatable balloon with a maximal diameter of $18 \mathrm{~mm}$ to allow acquisition of high-resolution images of the central airway wall and surrounding tissues (Figure 2). As mentioned above, use of this modality for guidance of TBNA has largely been abandoned in favor of real-time guidance with cpEBUS and in addition, manufacturing of certain parts required for implementation this modality has been discontinued by Olympus ${ }^{\mathrm{TM}}$.

Direct contact rpEBUS probes are available in an outer diameter of 1.7 to $2.5 \mathrm{~mm}$ and provide high-resolution images in the range of 12 to $30 \mathrm{MHz}$ (Figure 2). A smallerdiameter probe can hence be potentially advanced via the working channel of a pediatric-size bronchoscope. Although their use in the central airways is feasible, these probes are more helpful in identifying small peripheral lung lesions to guide sampling $(2,3,75)$ and perhaps therapy (76). In their case series, Koh et al. utilized rpEBUS to guide sampling of peripheral lung consolidation in two critically ill patients, both of whom were ultimately diagnosed with lung adenocarcinoma. No procedure-related complications were reported (31). Nonetheless, the potential applications of direct contact-rpEBUS in mechanically ventilated, critically ill patients remain limited, and if pursued, should be performed by experienced providers.

\section{Conclusions}

EBUS has revolutionized diagnostic bronchoscopy. Although conventionally used for evaluation and sampling of mediastinal and hilar lymph nodes, the application of EBUS bronchoscopy in critically ill patients can also be considered in a variety of other benign and malignant conditions, ranging from central airway obstruction to peripheral lung lesions. These applications, however, are limited by technical and human factors inherent to the EBUS procedure, including need for dedicated equipment, trained and experienced operators and support team, prolonged procedure time, and airway obstruction by the relatively bulky EBUS bronchoscope. Moreover, limited data to guide optimal patient selection and procedure performance limits extrapolation of currently available data to the general critically ill patient population. Nonetheless, the available literature is encouraging as it offers singlecenter experiences of safe use of EBUS bronchoscopy that yielded changes in management. At the same time, these reports reinforce the importance of judicious patient selection and procedure performance by experienced personnel.

\section{Acknowledgments}

Funding: This work was supported by the Memorial Sloan Kettering Cancer Center Support Grant/Core Grant (P30 CA008748).

\section{Footnote}

Provenance and Peer Review: This article was commissioned by the Guest Editors (Jonathan S. Kurman, Ashutosh 
Sachdeva and Rahul Nanchal) for the series "Interventional Pulmonology in the Intensive Care Unit Environment" published in Fournal of Thoracic Disease. The article has undergone external peer review.

Conflicts of Interest: All authors have completed the ICMJE uniform disclosure form (available at: http://dx.doi. org/10.21037/jtd-2019-ipicu-09). The series "Interventional Pulmonology in the Intensive Care Unit Environment" was commissioned by the editorial office without any funding or sponsorship. The authors have no other conflicts of interest to declare.

Ethical Statement: The authors are accountable for all aspects of the work in ensuring that questions related to the accuracy or integrity of any part of the work are appropriately investigated and resolved.

Open Access Statement: This is an Open Access article distributed in accordance with the Creative Commons Attribution-NonCommercial-NoDerivs 4.0 International License (CC BY-NC-ND 4.0), which permits the noncommercial replication and distribution of the article with the strict proviso that no changes or edits are made and the original work is properly cited (including links to both the formal publication through the relevant DOI and the license). See: https://creativecommons.org/licenses/by-nc-nd/4.0/.

\section{References}

1. Hurter T, Hanrath P. Endobronchial sonography: feasibility and preliminary results. Thorax 1992;47:565-7.

2. Eberhardt R, Anantham D, Ernst A, et al. Multimodality bronchoscopic diagnosis of peripheral lung lesions: a randomized controlled trial. Am J Respir Crit Care Med 2007;176:36-41

3. Herth FJ, Eberhardt R. Endobronchial ultrasound and electromagnetic navigation bronchoscopy in the diagnosis of peripheral lung lesions. Expert Opin Med Diagn 2008;2:461-6.

4. Yasufuku K, Chiyo M, Sekine Y, et al. Real-time endobronchial ultrasound-guided transbronchial needle aspiration of mediastinal and hilar lymph nodes. Chest 2004;126:122-8

5. Wahidi MM, Herth F, Yasufuku K, et al. Technical Aspects of Endobronchial Ultrasound-Guided Transbronchial Needle Aspiration: CHEST Guideline and Expert Panel Report. Chest 2016;149:816-35.
6. Adam AK, Soubani AO. Outcome and prognostic factors of lung cancer patients admitted to the medical intensive care unit. Eur Respir J 2008;31:47-53.

7. Darmon $M$, Thiery G, Ciroldi $M$, et al. Intensive care in patients with newly diagnosed malignancies and a need for cancer chemotherapy. Crit Care Med 2005;33:2488-93.

8. Decavèle M, Gounant V, Fleury Feith J, et al. Endobronchial ultrasound-guided transbronchial needle aspiration is feasible, safe, and reaches a $90 \%$ diagnostic yield in patients with hypoxemic acute respiratory failure. Intensive Care Med 2016;42:1295-8.

9. Li P, Wu C, Zheng $\mathrm{W}$, et al. Pathway and application value of exploration of the pulmonary artery by endobronchial ultrasound. J Thorac Dis 2017;9:5345-51.

10. Lindholm CE, Ollman B, Snyder JV, et al. Cardiorespiratory effects of flexible fiberoptic bronchoscopy in critically ill patients. Chest 1978;74:362-8.

11. Ricou B, Grandin S, Nicod L, et al. Adult and paediatric size bronchoscopes for bronchoalveolar lavage in mechanically ventilated patients: yield and side effects. Thorax 1995;50:290-3.

12. Ergan B, Nava S. The use of bronchoscopy in critically ill patients: considerations and complications. Expert Rev Respir Med 2018;12:651-63.

13. Estella A. Bronchoscopy in Mechanically Ventilated Patients. In: Haranth SP, editor. Global Perspective on Bronchoscopy. InTech; 2012. p. 91-106.

14. Kalchiem-Dekel O, Shanholtz CB, Jeudy J, et al. Feasibility, safety, and utility of bronchoscopy in patients with ARDS while in the prone position. Crit Care 2018;22:54.

15. Albertini RE, Harrell JH, 2nd, Kurihara N, et al. Arterial hypoxemia induced by fiberoptic bronchoscopy. Jama 1974;230:1666-7.

16. Dubrawsky C, Awe RJ, Jenkins DE. The effect of bronchofiberscopic examination on oxygenation status. Chest 1975;67:137-40.

17. Lawson RW, Peters JI, Shelledy DC. Effects of fiberoptic bronchoscopy during mechanical ventilation in a lung model. Chest 2000;118:824-31.

18. Nakstad ER, Opdahl H, Skjonsberg OH, et al. Intrabronchial airway pressures in intubated patients during bronchoscopy under volume controlled and pressure controlled ventilation. Anaesth Intensive Care 2011;39:431-9.

19. Nay MA, Mankikian J, Auvet A, et al. The effect of fibreoptic bronchoscopy in acute respiratory distress 
syndrome: experimental evidence from a lung model. Anaesthesia 2016;71:185-91.

20. Davies L, Mister R, Spence DP, et al. Cardiovascular consequences of fibreoptic bronchoscopy. Eur Respir J 1997;10:695-8.

21. Grosu HB, Morice RC, Sarkiss M, et al. Safety of flexible bronchoscopy, rigid bronchoscopy, and endobronchial ultrasound-guided transbronchial needle aspiration in patients with malignant space-occupying brain lesions. Chest 2015;147:1621-8.

22. Kerwin AJ, Croce MA, Timmons SD, et al. Effects of fiberoptic bronchoscopy on intracranial pressure in patients with brain injury: a prospective clinical study. J Trauma 2000;48:878-82; discussion 882-3.

23. Peerless JR, Snow N, Likavec MJ, et al. The effect of fiberoptic bronchoscopy on cerebral hemodynamics in patients with severe head injury. Chest 1995;108:962-5.

24. Brochard L, Mion G, Isabey D, et al. Constant-flow insufflation prevents arterial oxygen desaturation during endotracheal suctioning. Am Rev Respir Dis 1991;144:395-400.

25. Maggiore SM, Lellouche F, Pigeot J, et al. Prevention of endotracheal suctioning-induced alveolar derecruitment in acute lung injury. Am J Respir Crit Care Med 2003;167:1215-24.

26. Greenstein YY, Shakespeare E, Doelken P, et al. Defining a Ventilation Strategy for Flexible Bronchoscopy on Mechanically Ventilated Patients in the Medical Intensive Care Unit. J Bronchology Interv Pulmonol 2017;24:206-10.

27. Estella A. Effects on respiratory mechanics of bronchoalveolar lavage in mechanically ventilated patients. J Bronchology Interv Pulmonol 2010;17:228-31.

28. Montravers P, Gauzit R, Dombret MC, et al. Cardiopulmonary effects of bronchoalveolar lavage in critically ill patients. Chest 1993;104:1541-7.

29. Kuo AS, Philip JH, Edrich T. Airway ventilation pressures during bronchoscopy, bronchial blocker, and double-lumen endotracheal tube use: an in vitro study. J Cardiothorac Vasc Anesth 2014;28:873-9.

30. Yarmus LB, Akulian J, Lechtzin N, et al. Comparison of 21-gauge and 22-gauge aspiration needle in endobronchial ultrasound-guided transbronchial needle aspiration: results of the American College of Chest Physicians Quality Improvement Registry, Education, and Evaluation Registry. Chest 2013;143:1036-43.

31. Koh MS, Ong TH, Phua GC, et al. Feasibility of endobronchial ultrasound in mechanically ventilated patients. Ann Acad Med Singapore 2014;43:238-40.

32. Rusch VW, Asamura H, Watanabe H, et al. The IASLC lung cancer staging project: a proposal for a new international lymph node map in the forthcoming seventh edition of the TNM classification for lung cancer. J Thorac Oncol 2009;4:568-77.

33. Herth FJ, Annema JT, Eberhardt R, et al. Endobronchial ultrasound with transbronchial needle aspiration for restaging the mediastinum in lung cancer. J Clin Oncol 2008;26:3346-50.

34. Yasufuku K, Nakajima T, Motoori K, et al. Comparison of endobronchial ultrasound, positron emission tomography, and CT for lymph node staging of lung cancer. Chest 2006;130:710-8.

35. Yasufuku K, Nakajima T, Fujiwara T, et al. Utility of endobronchial ultrasound-guided transbronchial needle aspiration in the diagnosis of mediastinal masses of unknown etiology. Ann Thorac Surg 2011;91:831-6.

36. Nakajima T, Yasufuku K, Kurosu K, et al. The role of EBUS-TBNA for the diagnosis of sarcoidosis-comparisons with other bronchoscopic diagnostic modalities. Respir Med 2009;103:1796-800.

37. Geake J, Hammerschlag G, Nguyen P, et al. Utility of EBUS-TBNA for diagnosis of mediastinal tuberculous lymphadenitis: a multicentre Australian experience. J Thorac Dis 2015;7:439-48.

38. Alraiyes AH, Almeida FA, Mehta AC. Pericardial recess through the eyes of endobronchial ultrasound. Endosc Ultrasound 2015;4:162-3.

39. Ashinuma H, Shingyoji M, Yoshida Y, et al. Endobronchial ultrasound-guided transbronchial needle aspiration in a patient with pericardial mesothelioma. Intern Med 2015;54:43-8.

40. Sharma RK, Khanna A, Talwar D. Endobronchial Ultrasound: A New Technique of Pericardiocentesis in Posterior Loculated Pericardial Effusion. Chest 2016;150:e121-3.

41. Rajan P, Kalanjeri S, Chawla M. Aspiration of Parabronchial Pleural Effusion Using Endobronchial Ultrasound. Chest 2013;144:29A.

42. Pickering EM, Holden VK, Heath JE, et al. Tissue Acquisition During EBUS-TBNA: Comparison of Cell Blocks Obtained From a 19G Versus 21G Needle. J Bronchology Interv Pulmonol 2019;26:237-44.

43. Kinoshita T, Ujiie H, Schwock J, et al. Clinical evaluation of the utility of a flexible 19-gauge EBUS-TBNA needle. J Thorac Dis 2018;10:2388-96.

44. Dooms C, Vander Borght S, Yserbyt J, et al. A 
Randomized Clinical Trial of Flex 19G Needles versus 22G Needles for Endobronchial Ultrasonography in Suspected Lung Cancer. Respiration 2018;96:275-82.

45. Herth FJ, Schuler H, Gompelmann D, et al. Endobronchial ultrasound-guided lymph node biopsy with transbronchial needle forceps: a pilot study. Eur Respir J 2012;39:373-7.

46. Darwiche K, Freitag L, Nair A, et al. Evaluation of a novel endobronchial ultrasound-guided lymph node forceps in enlarged mediastinal lymph nodes. Respiration 2013;86:229-36.

47. O'Brien JD, Ettinger NA, Shevlin D, et al. Safety and yield of transbronchial biopsy in mechanically ventilated patients. Crit Care Med 1997;25:440-6.

48. Chichra A, Lakticova V, Koeing S. The safety and role of endobronchial ultrasound-guided transbronchial needle aspiration (EBUS-TBNA) in the medical intensive care unit (MICU). CHEST Annual Meeting; Montreal, Canada, 2015.

49. Chichra A, Lama KW, Koenig SJ. Respiratory failure with hilar mass: Role of endobronchial ultrasound-guided transbronchial needle aspiration in the medical intensive care unit. Lung India 2015;32:178-81.

50. Michaud GC. Basic principles of TBNA. In: Mehta AC, Jain P, editors. Interventional Bronchoscopy. 1st edition ed. New York: Springer; 2013. p. 25-43.

51. Herth FJ, Becker HD, Ernst A. Ultrasound-guided transbronchial needle aspiration: an experience in 242 patients. Chest 2003;123:604-7.

52. Ghamande S, Rafanan A, Dweik R, et al. Role of transbronchial needle aspiration in patients receiving mechanical ventilation. Chest 2002;122:985-9.

53. Stather DR, Jarand J, Silvestri GA, et al. An evaluation of procedural training in Canadian respirology fellowship programs: program directors' and fellows' perspectives. Can Respir J 2009;16:55-9.

54. Wahidi MM, Silvestri GA, Coakley RD, et al. A prospective multicenter study of competency metrics and educational interventions in the learning of bronchoscopy among new pulmonary fellows. Chest 2010;137:1040-9.

55. Wallace MB, Silvestri GA, Sahai AV, et al. Endoscopic ultrasound-guided fine needle aspiration for staging patients with carcinoma of the lung. Ann Thorac Surg 2001;72:1861-7.

56. Liberman M, Duranceau A, Grunenwald E, et al. New technique performed by using EUS access for biopsy of para-aortic (station 6) mediastinal lymph nodes without traversing the aorta (with video). Gastrointest Endosc
2011;73:1048-51.

57. Nasir BS, Edwards M, Tiffault V, et al. Transesophageal pulmonary nodule biopsy using endoscopic ultrasonography. J Thorac Cardiovasc Surg 2014;148:8505; discussion 5.

58. Chang JI, Kwok KK. EUS-FNA of a Compressive Left Ventricular Intrapericardial Mass. Am J Gastroenterol 2016;111:1229.

59. Chang KJ, Erickson RA, Nguyen P. Endoscopic ultrasound (EUS) and EUS-guided fine-needle aspiration of the left adrenal gland. Gastrointest Endosc 1996;44:568-72.

60. Herth FJ, Krasnik M, Kahn N, et al. Combined endoscopic-endobronchial ultrasound-guided fine-needle aspiration of mediastinal lymph nodes through a single bronchoscope in 150 patients with suspected lung cancer. Chest 2010;138:790-4.

61. Hwangbo B, Lee HS, Lee GK, et al. Transoesophageal needle aspiration using a convex probe ultrasonic bronchoscope. Respirology 2009;14:843-9.

62. Prasad KT, Sehgal IS, Gupta N, et al. Endoscopic ultrasound (with an echobronchoscope)-guided fineneedle aspiration for diagnosis of a mediastinal lesion in a mechanically ventilated patient: A case report and systematic review of the literature. Indian J Crit Care Med 2016;20:608-12.

63. Berzosa M, Davies SF, Gupta K, et al. Diagnostic bedside EUS in the intensive care unit: a single-center experience. Gastrointest Endosc 2013;77:200-8.

64. Bhaskar N, Shweihat YR, Bartter T. The intubated patient with mediastinal disease--a role for esophageal access using the endobronchial ultrasound bronchoscope. J Intensive Care Med 2014;29:43-6.

65. Sachdeva A, Lee HJ, Malhotra R, et al. Endobronchial ultrasound diagnosis of pulmonary embolism. J Bronchology Interv Pulmonol 2013;20:33-4.

66. Channick CL, Channick RN. Use of Endobronchial Ultrasound for Bedside Diagnosis of Acute Pulmonary Embolism in a Critically Ill Patient. Chest 2019;155:651-2.

67. Aumiller J, Herth FJ, Krasnik M, et al. Endobronchial ultrasound for detecting central pulmonary emboli: a pilot study. Respiration 2009;77:298-302.

68. Harris K, Modi K, Kumar A, et al. Endobronchial ultrasound-guided transbronchial needle aspiration of pulmonary artery tumors: A systematic review (with video). Endosc Ultrasound 2015;4:191-7.

69. Li P, Zheng W, Zhao L. Convex probe endobronchial ultrasound: applications beyond conventional indications. J 
Thorac Dis 2015;7:E289-97.

70. Al-Ajam MR, Kalanjeri S, Haas AR, et al. Endobronchial ultrasound. When to venture into the vasculature. Ann Am Thorac Soc 2013;10:393-5.

71. Chamorro N, Blanco I, Sanchez M, et al. The expanding horizons of endobronchial ultrasound: diagnosis of a tumor embolism. Chest 2012;142:1334-6.

72. Lee SJ, Lee J, Yu SJ, et al. Timely diagnosis of pulmonary artery tumor embolism by ultrasoundguided transbronchial needle aspiration. Thorac Cancer 2014;5:184-7.

73. Schuuring MJ, Bonta PI, van Vugt M, et al.

Cite this article as: Kalchiem-Dekel O, Hossain S, Gauran C, Beattie JA, Husta BC, Lee RP, Chawla M. An evolving role for endobronchial ultrasonography in the intensive care unit. J Thorac Dis 2021;13(8):5183-5194. doi: 10.21037/jtd-2019-ipicu-09
Endosonography of a Pulmonary Artery Obstruction in Echinococcosis. Respiration 2016;92:425-7.

74. Hsu AL. Critical airway obstruction by mediastinal masses in the intensive care unit. Anaesth Intensive Care 2013;41:543-8.

75. Asano F, Eberhardt R, Herth FJ. Virtual bronchoscopic navigation for peripheral pulmonary lesions. Respiration 2014;88:430-40.

76. Zheng X, Yang C, Zhang X, et al. The Cryoablation for Peripheral Pulmonary Lesions Using a Novel Flexible Bronchoscopic Cryoprobe in the ex vivo Pig Lung and Liver. Respiration 2019;97:457-62. 